\title{
The ethics of reusing single-use devices
}

$\mathrm{T}$

he topic of reprocessing medical devices labelled as single-use is something of an ethical quagmire. The only thing clear about this issue, it seems, is that it's complicated and encompasses many areas, including patient safety, fiscal responsibility and environmental stewardship.

"The reuse of SUIs [single-use items] is an extraordinarily complex issue," Alice Moszczynski, a registered nurse in Terrace, British Columbia, wrote in a paper (J Med Ethics 2009;35:87-90).

Single-use medical items, like any disposable product, are convenient. Instead of repairing, cleaning and sterilizing a used device, a health care provider can just open a new one. But unlike paper plates, disposable medical devices can be expensive. A single-use ultrasound catheter can cost as much as $\$ 5000$. Furthermore, some devices are robust enough for multiple uses, despite the labels on their packaging.

So it has become a common practice in many hospitals to reprocess single-use medical devices (www.cmaj.ca/lookup /doi/10.1503/cmaj.109-3906). When a hospital adopts a reuse policy, many ethical issues arise, such as patient consent. It could be argued that consent isn't necessary if a hospital already has policies to ensure reused items are as safe and effective as new ones. Informing the patient could lead to unwarranted worry. "They may think they are getting a lower standard of care, even though the items are resterilized," says Moszczynski.

On the other hand, reusing a singleuse device without consent could be viewed as "hidden rationing," and does not respect a patient's autonomy. After all, there is little evidence that reprocessed items are as safe as new ones, and common sense dictates that the more times something is used the more likely it is to malfunction. And since no process is perfect, the odds of infection will be higher, if only slightly, when a device is used on more than one patient.

"The healthcare worker and system would be viewed in a positive light by sharing this information with patients rather than seen as exploiting patients in a vulnerable situation," Moszczynski states in her paper.
The ethics of fiscal responsibility also come into play. From a utilitarian stance, it could be viewed as unethical to use an item once if it can be safely used again. To do so burdens taxpayers, who foot the bill, and will only lead to sacrifices in other areas of health care.

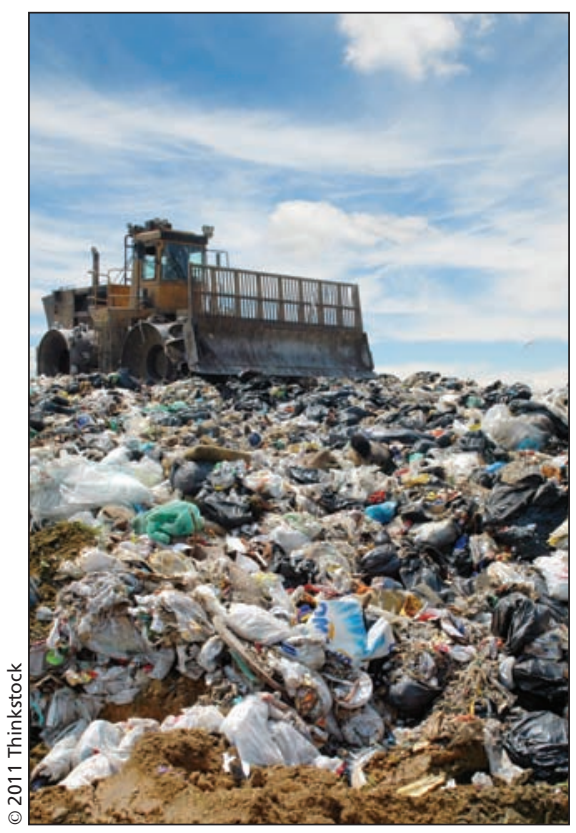

The US health care sector follows only the food industry in contributing to landfills. Reprocessing single-use medical devices could reduce medical waste.

It is also important to remember that the parties deciding which medical items are single-use are device manufacturers, who stand to profit more if hospitals replace rather than reuse their products. "The stipulation that a SUI [single-use device] never be reused places the healthcare system and society at large in a position of financial hostage to manufacturers," Moszczynski suggests in her paper. Another study estimates that $10 \%-20 \%$ of single-use devices are actually incorrectly labelled multiple-use devices (IJHEH 2010; 213:302-7).

"The manufacturers will make a statement that the device is single-use only and that it's in the best interest of patients to throw them out, whereas hospitals may turn around and argue that perhaps the manufacturers' intentions do not relate to patient safety," says Julie Polisena, clinical research manager for the Canadian Agency for
Drugs and Technologies in Health, who led a survey that found that $28 \%$ of Canadian hospitals reprocess single-use items (www.cadth.ca/en/products/health -technology-assessment/publication/800).

Reuse advocates estimate that hospitals save up to $50 \%$ by reprocessing single-use devices. For example, a Banner Health hospital in Phoenix, Arizona, saved US $\$ 1.5$ million in a year by reprocessing such devices as compression sleeves, catheters and pulse oximeters.

Canadian hospitals would not likely experience comparable savings. "The problem in Canada is that there are no third-party reprocessing companies," says Moszczynski. "If hospitals got together and tried to send items out and there were third-party reprocessors, that would save money. We are throwing stuff out or donating it to other countries and there is a lack of education on why we can't reuse it. It's an unresolved dilemma at the moment."

Another argument against seeking savings through reuse is that ignoring manufacturer instructions could have legal ramifications if patients suffer harm after being treated with reused devices. Financial gains could be lost if hospitals are dragged into costly lawsuits.

A third ethical consideration is environmental stewardship. According to one study, the US health care sector is second only to the food industry in contributing to landfills, disposing of an estimated four billion pounds of medical waste annually (Acad Med 2010;85:398-400). "Health care can contribute to creating a livable planet by reducing the substantial amount of waste it produces," the paper concludes. "Reprocessing is one strategy to accomplish this."

Perhaps the best solution to the many ethical dilemmas around reuse is not to reprocess single-use medical devices, suggests Moszczynski, but rather to do away with them altogether. "Instead of saying we are a disposable society, let's step back and see how we can do it differently," she says. "How can we design these devices so they can be reused and still meet the needs of patients?" Roger Collier, CMAJ

CMAJ 2011. DOI:10.1503/cmaj.109-3907 